\title{
Watching and Being Watched: Gender and Space in the Painting of the Qianlong Emperor's Southern Inspection Tour with a Comparative View
}

\section{Yuzhou Wang}

Xi'an Jiaotong Liverpool University, Department of Architecture, Suzhou, China

\section{Abstract}

This article explores the female space in the painting of Qianlong Southern Inspection Tour, which depicts the daily life and activities of the eighteenth-century Chinese city Suzhou. From the observation of the painting, there are semi-open spaces along the streets in which females stand and watch the imperial parade. Women tended to be invisible in the public circumstance during feudal periods: this research analyses the presence and role of these female spaces and whether they can be seen as a

Corresponding Author:

Yuzhou Wang

Yuzhou.Wang15@student.xjtlu .edu.cn

Received: 15 March 2019

Accepted: 25 May 2019

Published: 20 November 2019

Publishing services provided by Knowledge E

(c) Yuzhou Wang. This article is distributed under the terms of the Creative Commons

Attribution License, which permits unrestricted use and redistribution provided that the original author and source are credited

Selection and Peer-review under the responsibility of the Architecture across Boundaries Conference Committee. step towards the modern space in the process of early-modern China. In analyzing these spaces, it focuses on the relation between the women's watching and being watched in the space, and how it represents the evolution of feminism consciousness in space in feudal times and, sequentially, how it evokes the consideration of feminist role in modern practice. The study shows that the semi-open space that hosts the female activities can be regarded as an epitome of negotiating space and gender in the urban context. Women in the painting were exposed to the public to a certain extent, while they were still within mental and physical boundaries in the female social structure of the Emperor Qianlong period. These negotiations indicate the transition of gender and space in the late Imperial China and present parts of the process of spatial modernization in the Jiangnan region. From the comparative perspective, this research further investigates the relationships of gender and space by focusing on the space along the streets in the Qianlong Southern Inspection Tour, located within the homogenous space of the Riverside Scene at Qingming Festival of Ming dynasty seen Canaletto's paintings of eighteenth-century Europe and Dianshi Zhai's pictorials of the late Qing period. The research traces space in these paintings and how it represents the feminism consciousness and the evolution of female space in different historical and cultural backgrounds by looking at the social relations of the production of the specific history of people's daily lives and the differences of social classes and nations.

Keywords: Female space, paintings, late imperial China, urban modernization 1. Introduction

'Places are made through power relations which construct the rules which define boundaries (McDowell, 1999, p.4).' During the feudal times, the the public area always preoccupied with men, while women tended to stay in the private area because the role of the wife in the house was idealized and confined by Confucian patriarchal systems. 
These boundaries are social and spatial, which define who belongs to a place and who may be not, and the location or site of the experience as well (McDowell, 1999, p.4). On the one side of the boundary, males were visible in public area and gradually became the master of spatial development, while females were invisible for most of the time on the other side of the boundary, and were trapped in the domestic sphere.

From the observation of the painting, the Qianlong Southern Inspection Tour, which depicts the daily life and activities of the eighteenth century Chinese city Suzhou, there are semi-open spaces along the streets in which females stand and watch the imperial parade, both to observe and be observed as well (Figure 1). As Lefebvre (1974) claimed, modern space is reflected in the analysis of production, that is the transition of the conception from 'production in space' to the 'production of space.' Therefore, whether the presence these female spaces create a new production of space, and whether can be seen as

a step towards the modern space in the process of early-modern China? This essay focus on the females' relationships of watching and being watched in the space, from the comparative perspective, analyze spatial gender relations mainly in the spaces along the streets in the Qianlong Southern Inspection Tour, the Riverside Scene at Qingming Festival of the Ming Dynasty, Canaletto's paintings of eighteenth- century Europe and the Dianshi Zhai's Pictorials of the late Qing period to study the representation and evolution of feminism consciousness in space in the feudal times of areas around Suzhou. In addition, the research is going to base on social relations of production of different periods, study daily life and figure out differences of nations and classes as well. Furthermore, contemporary space in Suzhou will be analyzed to present the evolution of the women's role in the public space.

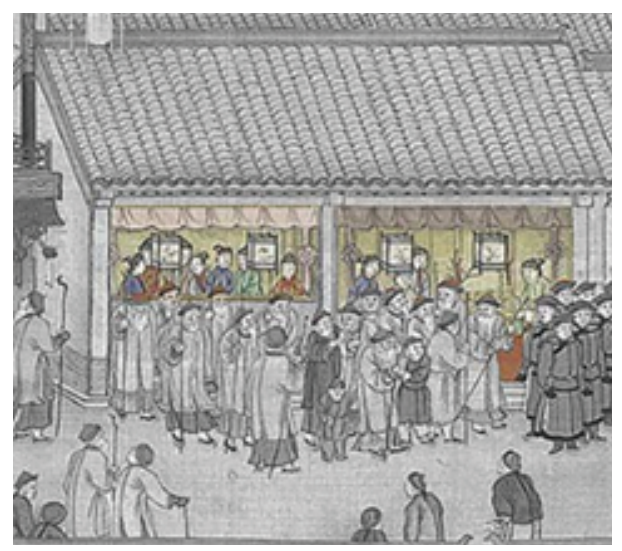

Figure 1: Xu, The Qianlong Southern Inspection Tour, about 1750. 


\section{Comparison}

\subsection{The Qianlong Southern Inspection Tour}

During the Emperor Qianlong Period, pre-globalization started to germinate because of the industrial revolution and colonial movement in the western world. In order to resist the trend, Emperor Qianlong adopted the foreign policy of isolationism. In addition, the country was under multiethnic domination, mainly Han and Man, and the social class divisions were very strict. In urban area, as shown in Figure 2, aristocrat females were always limited in layers of boundaries. The gates acted as warning cordon. Because of the strict Confucian family system and abnormal aesthetic, women tended to bind feet and built up chastity arch to exhibit their purity. However, in rural areas, owing to the thriving handicraft industry in the Jiangnan region, civilian women got involved in the productive process, they were more movable and fewer boundaries (Figure 3).

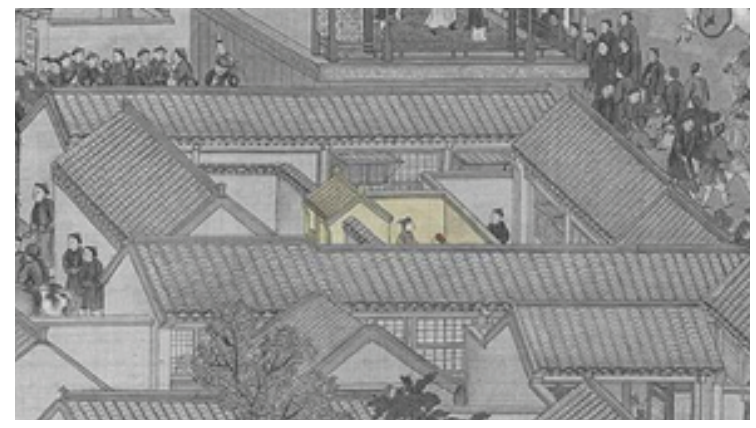

Figure 2: Women in urban area (Xu, about 1750).

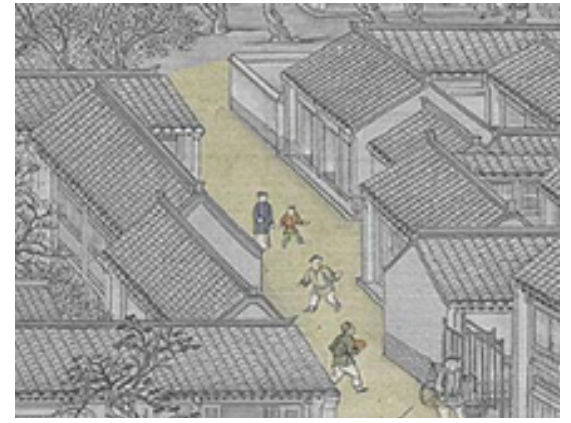

Figure 3: Women in rural area (Xu, about 1750).

In the spaces along the street, as shown in the Figure 4, female can observe and take part in activities on the streets to a certain extent, while the wicket gates (Figure 5) acted as semi-blurred boundaries to protect women's privacy and reduced their interaction with the outside world (Huang, 2008, own translation from the Chinese text). Women also chose to stay in their backyard to reduce exposure to the public (Figure $6)$, which also reduced the risk of being reproached. Additionally, the enclosures used 
as separations acted as boundaries lessen the views from observers. However, there exists a special case,

actresses, who were regarded as commodities rather than females, performed in the pavilion on the roof and completely exposed to the public (Figure 7).

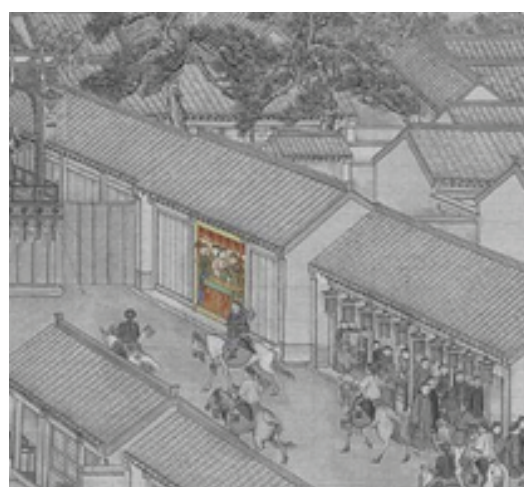

Figure 4: Standing by the streets (Xu, about 1750).

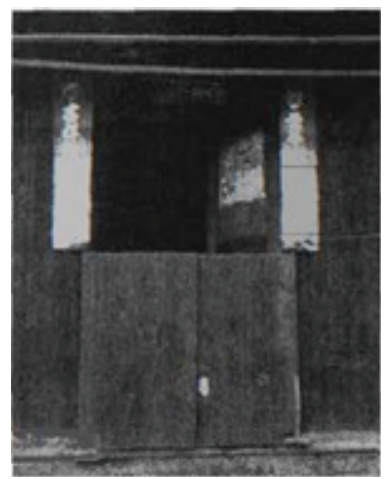

Figure 5: Wicket gate (Yi, 2005)

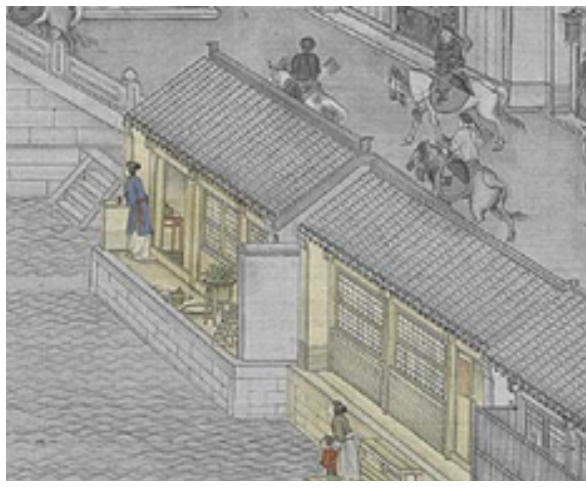

Figure 6: Women stayed in the backyard (Xu, about 1750).

Except for the situation of the pavilion on the roof (Figure 8a), both the spaces behind the wicket gates (Figure 8b) and the backyard area (Figure 8c) demonstrate that females were within physical and mental limitations, they want to observe, while they were ashamed to be observed. Beauvoir stated in her book, The Second Sex (1949), that 


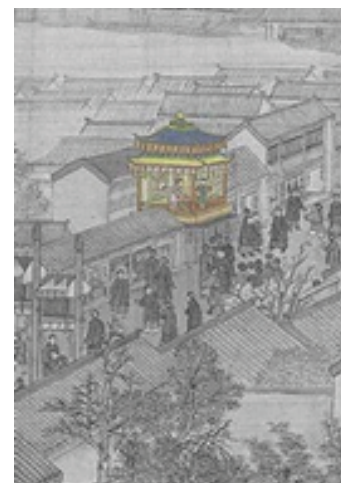

Figure 7: Actress (Xu, about 1750).

what makes a woman a woman is not her biological sex, but her social sex. Admittedly, the social division of females is a significant factor leading to the distinction of gender geography. As Firestone (1970) asserted, however, gender division is the foundation to form the division of class and nation, and the social differences between males and females are determined by their physiological differences. Because of their role of fertility and raising children, women's dependence on men has resulted in their subordination to men. The spaces in the painting reflect this relation, unless she had to be involved in the production, women were supposed to stay in boundaries. In consequence, when women had consciousness of being inferior to men and tried to hide behind boundaries, the area they stayed in was branded as subordinate space, while males controlled the dominant power of the space definition.

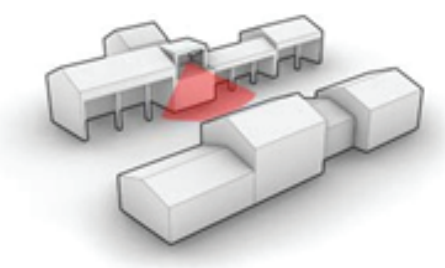

(a)

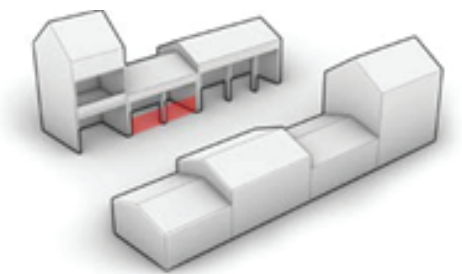

(b)

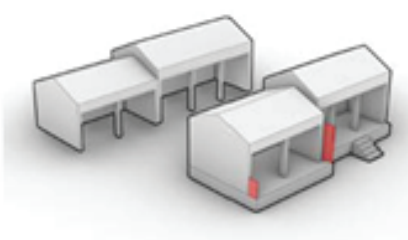

(c)

Figure 8: (a) Pavilion on the roof (produce by author). (b) Space with wicket gate facing the streets (produce by author). (c) Backyard space (produce by author).

\subsection{The Riverside Scene at Qingming Festival}

The Riverside Scene at Qingming Festival portrays the urban impression of Suzhou in the Ming Dynasty. The pleasure quarter played a significant role in the flourishing cultural scene of the Jiangnan region during the Ming Dynasty, commerce and entertainment industries were thriving. Merlin (2012) pointed out that women were encouraged to be well-educated and establish certain literature attainment. Courtesans, especially, 
whose careers were highly dependent on their visibility and sociability, and thus had more mobility in the city (Figure 9a). In addition, because of the bustling economy in Jiangnan region, women mainly working in the textile sector, fueled the production process to meet the supply for huge demand in the market (Bray, 1997). Both the promoting educational capacity and manual skills improved women's social role, females had more freedom to move in the city. As shown in Figure 9b, two women sat by the window on the river, enjoying the folk performances across the river. In addition, there was a woman who is breastfeeding and facing the busy street (Figure 9c), they sat by the window and entrances, being at ease with exhibiting their daily life and observing outside activities freely. Both men and women do not feel shame to face each other.

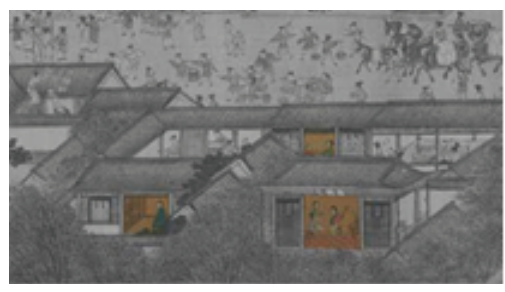

(a)

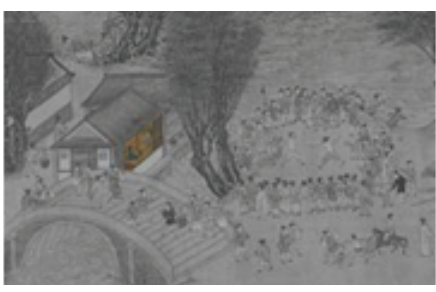

(b)

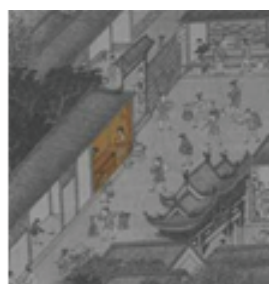

(c)

Figure 9: (a) Qiu, The Riverside Scene at Qingming Festival, about 1500. (b) Women sitted by the window (Qiu, about 1500). (c) Women is breastfeeding (Qiu, about 1500).

Although still stayed in the domestic sphere mostly, compared with the conditions in the Qianlong Southern Inspection Tour, females in the Ming Dynasty had fewer boundaries to move outside and more freedom to show themselves. As shown in Figure 10, the spaces by the window and along the street acted as open auditoriums, while they were also observed to a large extent. 'The courtesans represented an extraordinary negotiation of gender and space boundaries,' Merlin (2012, p.140) stated. The mobility and visibility of courtesans broke the traditional Confucian spatial order. Furthermore, as indicated in the Human Geography today (Massey, 1999), the product of relations are active practices that have to be carried out, space is always in processing of becoming, and being made as well. Therefore, spatial subordination based on gender reduced to in a sense, since women had free consciousness to be watched, and the gender relations altered in the spaces.
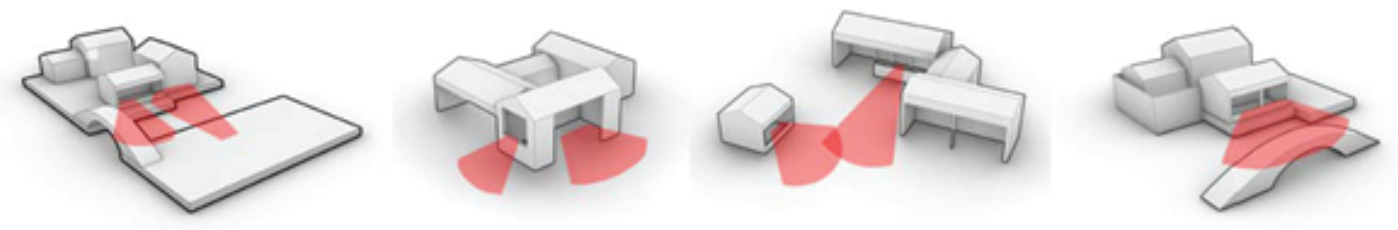

Figure 10: Spaces along the streets (produce by author). 


\section{Venetian Scenes by Canaletto}

Venice in the eighteenth century was under the historical background that after the renaissance, early industry revolution and capitalism started to germinate. Women pursed beauty bravely and want to show themselves with extrinsic decoration. In addition, female of patricians had equal opportunities to be educated to achieve the perfection of personality (Cowan, 2007). Moreover, women moved out from home, employed as workers to satisfy the production demands of the growing industrial revolution. However, only not females' social role changed, males' social character also altered and became the masters of the production structure of the development of capitalism, still occupying the public area (Cowan, 2012).

Compared with the space in Chinese paintings, the space of balconies is more public, which can both be seen as an auditorium and a stage. As Cowan (2012, p.235) argued, 'Balconies are both places from which to observe and on which to be observed, and anyone who used a balcony was fully aware of this.' A Regatta on the Grand Canal (Figure 11), painted by Canaletto, depicts a spectacular scene that Henry III travelled in procession along the Grand Canal. Patrician women, especially, dressed up perfectly and stayed out on their balconies, not only to see, but also to crave attention, and 'the use of balconies as the equivalent of theatre boxes for less entertainments were just as temporary (Cowan, 2012, p. 235)'. Additionally, to take advantage of the sunlight, women would like to do some manual activities such as sewing on their balconies.

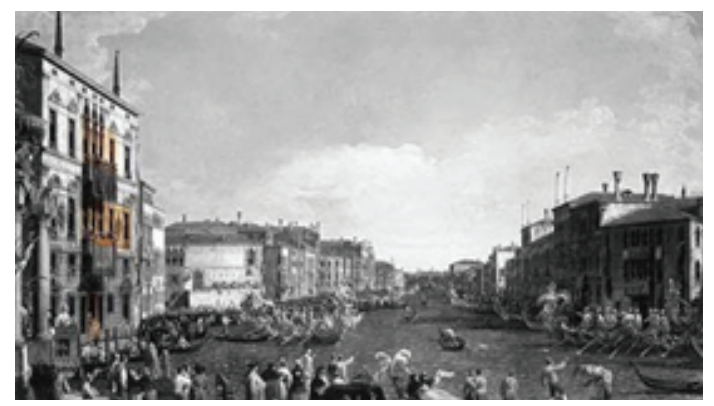

Figure 11: Canaletto, A Regatta on the Grand Canal, about 1740.

The emergence of balconies along the canal established the transition that female space gradually moved out of the domestic sphere, and they abandoned dependent consciousness in these spaces. As the need to look up to be watched, the balconies were seen as semi-open display spaces, and handrails were regarded as semi-blurred boundaries reducing views and interactions to some extent (Figure 12). Additionally, in comparison to the spaces along the streets in the Qianlong Southern Inspection Tour, the balconies in A Regatta on the Grand Canal increased the role of stages 
that women yearned for observations. Cowan (2012, p.244) raised the assertion that 'in gender terms, Venetian balconies were more of a woman's space than a man's.' If the spatial definition attributes only by gender, there will be limitations. As claimed by Bondi (1993, p.243), boundaries between nation and market, open and private were reorganized across Europe, catalyzing important changes in females' lives. In the process of women's negotiation of boundaries, spatial gender relations were fluctuating as well. The balconies tended to be transitional spaces from internal to external, from private to public, guiding women to step out from indoor space and display themselves freely.

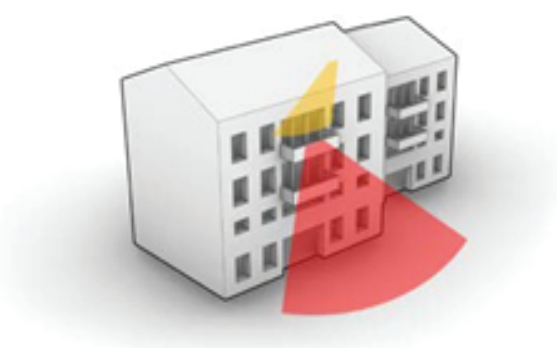

Figure 12: Balconies acted as stages (produce by author).

\subsection{The Dianshi Zhai's Pictorials}

The First Opium War was regarded as the beginning of stepping to the modern China. Resulted from the western colonial movement and early industrial civilization from Western countries, many places such as Shanghai opened trade ports and built foreign settlements. A great number of merchants migrated into Shanghai to seek for a job. The imported culture combined with feudal traditions and Confucian system order come to form a new immigrant civic culture (Liang, 2018, p.2, own translation from the Chinese text). Men felt stressed in their traditional families who were under strict Confucian systems. Thus they were inclined to pursue an ideal home - brothel. The integration of Chinese and Western culture, as well as the growing industries in Shanghai, resulted in the bustling scene of prostitution.

Followed by a typical pattern of admiration and imitation, Shanghai assimilated Western modernity, mixing its characteristics (Lee, 2001, p.6). Lilong, as a product of the new immigrant civic culture, penetrated with streets. These new living spaces reduced layers of boundaries; females lived in the rooms by the streets, watching the activities around and chatting with people on the ground (Figure 13a). Most prostitutes had the freedom to move in and out of their houses since prostitutes formed their family system 
without the command of males. One significant factor they needed to consider was their guests, and for the convenience of receiving guests, prostitutes still spent most of their time indoors. In addition, based on the rules of capitalism, inferior prosititutes lived in the tatty Lilong which were located at the perimeter of busy areas (Figure 13b). However, courtesans lived in new Lilong which were the early form of the apartment and located on the main streets (Figure 13c). Taking advantage of the location, courtesans stayed out on the balconies to attract people crowding busy streets, which became parts of the street scene.

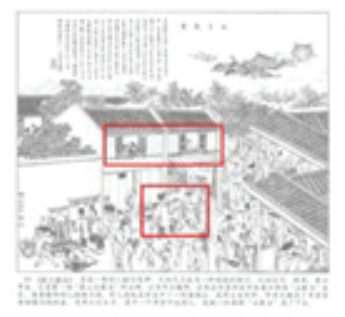

(a)

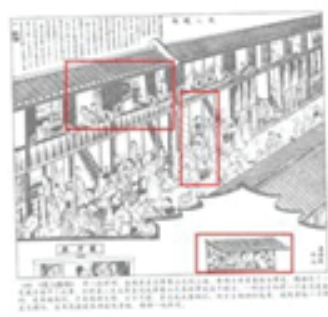

(b)

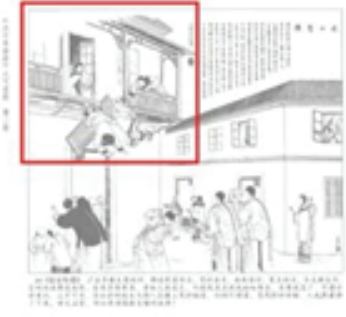

(c)

Figure 13: (a) Lilong space by the street (Wu, 2001). (b) Brothel at the perimeter of the busy area (Wu, 2001). (c) Courtesans stayed on the balconies (Wu, 2001).

The rise of prostitutions broke the old spatial pattern of the traditional gender rules. These spaces were both private space and open business space, females acted optionally and displayed themselves generously to attract visitors (Figure 14). Liang (2018, p.54, own translation from the Chinese text) wraps up with the bracing statement that courtesans became the master of these special commercial space, therefore, reversed internal and external space, and gender consciousness. As a consequence of the change of observing relationships and consciousness, the subordination of space transformed accordingly, males were not dominant in these spaces.
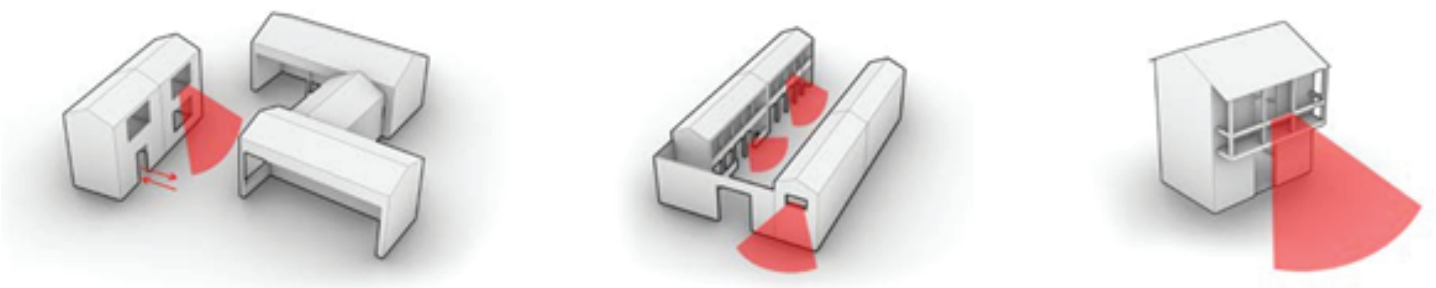

Figure 14: Prostitutions along the streets (produce by author).

\section{Contemporary Suzhou}

Due to the change of social structure and production structure in contemporary Suzhou, as well as the evolving female consciousness, new gender relations and female space 
are produced accordingly. As mentioned in the Research of Urban Women Social Space (Huang, 2008), the continuous prosperity of the market has catalyzed the development of consumerism and consumer culture in China. Women have changed their subordinate status in the production field into the dominant position in the current consumption field, and their influence on urban development is strengthening. As with the rise of women merchandise, female-dominated spaces, such as women's street, are springing up. As shown in Figure 15, women's streets are covered by shelters. The shelters reveal that women want to protect their privacy to a certain extent, while the covers also blur the boundary between outdoor and indoor area. Women make full use of these ambiguous spaces, which displays females' own creativity and diversity. The emergence of public spaces dominated by women does not fundamentally change the gender inequality in public space. However, since the relation of social production are constantly adjusted, and females' self-awareness and independence are growing, females are producing their own spaces and new social relationships, which promotes the diversity of gender spatial relations, urban tertiary industry, and urban life.
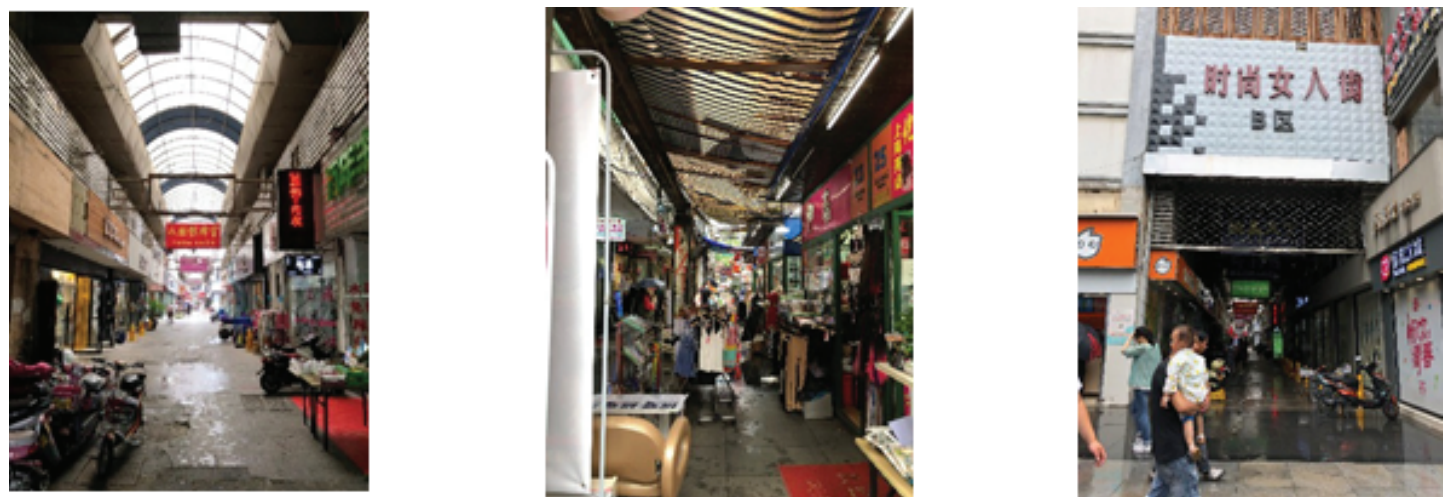

Figure 15: Women's streets in Suzhou (Yao, 2018).

\section{Conclusion}

The nature of space tends to change with the consciousness of occupants. The purpose of researching the relationships of watching and being watched is to embody women's consciousness concretely, thus expound the spatial gender relationship in detail. Females' consciousnesses are mainly affected by social production and class divisions. Given that the female spaces along the street in the Qianlong Southern Inspection Tour were under the traditional social structure of production and strict social division, females were treated as accessories, the spaces they stayed in were within both physical and mental boundaries. However, as shown in the Riverside Scene at 
Qingming Festival, women had more freedom in the Ming Dynasty, the spaces by the windows could be seen as epitomes of phenomena that spatial gender subordination was weakened. In the eighteenth century, Venice was under the great social revolution, females', as well as males, role in the social production altered significantly, and women's attitudes of self-presentation had also changed. The balconies above the canal could be regarded as transitional spaces that negotiate the gender relationships between public and private areas. Furthermore, prostitutions in the Dianshi Zhai's Pictorials reversed the spatial gender relationship, breaking the boundaries established by the old traditions. In contemporary Suzhou, because of the change of market structure and female consciousness, women are increasingly involved in public areas. As a conclusion, space is always in the process of evolution, new nature and structure of space are created with the generation of spatial gender relationship.

\section{Acknowledgement}

I am very thankful to Jiawen Han who gave me valuable inputs to the manuscript and helped in completing the paper.

\section{Conflict of Interest}

The authors have no conflict of interest to declare.

\section{References}

[1] Beauvoir, S. (1949). The Second Sex. London: Lowe and Brydone Ltd.

[2] Bondi, L. (1993). 'Gender and Geography: Crossing Boundaries', Human Geography Today, 17(2), June, pp. 241-246.

[3] Bray, F. (1997). Technology and Gender: Fabrics of Power in Late Imperial China. Berkeley: University of California Press.

[4] Cowan, A. (2007). Marriage, Manners and Mobility in Early Modern Venice. Burlington: Ashgate Publishing Limited.

[5] Cowan, A. (2012). 'Seeing is Believing: Urban Gossip and the Balcony in Early Modern Venice'. In: Foxhall, L., and Neher, G. (eds.) Gender and the City before Modernity. Wiley- Blackwell Publishing Ltd.

[6] Firestone, S. (1970). The Dialectic of Sex: The Case for Feminist Revolution. The Women's Press 
[7] Huang, C. (2008). 城市女性社会空间研究, Chinese: Research of Urban Women Social Space. Nanjing: Dongnan University Press.

[8] Lee, L. (2001). Shanghai Modern: The Flowering of a new urban culture in China, 1930- 1945. London: Harvard University Press.

[9] Lefebvre, H. (1974). The Production of Space. Oxford: Basil Blackwell Ltd.

[10] Liang, Y. (2018). 海上空间-晚清寓居城市的现代性, Chinese: Space in Shanghai the modernity of living cities in the late Qing Dynasty. Shanghai: Shanghai Cishu press.

[11] Massey, D. (1999). Human Geography Today. Cambridge: Polity.

[12] McDowell, L. (1999). Gender, Identity and Space. Minneapolis: University of Minnesota Press.

[13] Merlin, M. (2012). 'The Nanjing Ciurtesan Ma Shouzhen (1548-1604): Gender, Space and Painting in the Late Ming Pleasure Quarter'. In: Foxhall, L., and Neher, G. (eds.) Gender and the City before Modernity. London: Wiley-Blackwell Publishing Ltd.

\section{List of Illustrations}

[1] Canaletto, (about 1740). A Regatta on the Grand Canal. London: The National Gallery

[2] Qiu, Y. (about 1500). The Riverside Scene at Qingming Festival. Liaoning: Liaoning Provincial Museum

[3] Wu, L (2001). The Dianshi Zhai's Pictorials. Shanghai: Shanghai Pictorial Press

[4] Xu, Y. (about 1750). The Qianlong Southern Inspection Tour. Beijing: National Museum of China

[5] Yao, Y. (2018). Women's Streets in Suzhou.

[6] Yi, T. (2005). Chinese Folk Houses and Traditional Culture. Chengdu: Sichuan Renmin Press 